\title{
Perancangan Buku Ilustrasi Sejarah Reformasi Gereja, untuk Anak Usia 6-8 Tahun di Sekolah Minggu GKKA-I Banjarbaru, Kalimantan Selatan
}

\author{
Albert Christian Purwanto ${ }^{1}$, dan Didit Prasetyo Nugroho, S.Sn., M.Sn² \\ 12 Program Studi Desain Komunikasi Visual, Villa Puncak Tidar N-01, Kota Malang, 65151 \\ Correspondence: 331710004@student.machung.ac.id (Albert Christian Purwanto) \\ Received: 290721 - Revised: 120821 - Accepted: 120821 - Published: 280921
}

\begin{abstract}
Abstrak. Pengenalan pengetahuan akan sejarah merupakan salah satu cara untuk memahami asal mula suatu kebudayaan maupun peradaban yang menjadi sebuah refleksi dari kejadian yang ada dimasa lampau agar dapat menjadi pedoman baik dimasa yang akan datang. Dalam Agama Kristen sejarah juga sebuah hal yang sangant penting. Salah satu sejarah yang mernarik yaitu sejarah yang berkaitan dengan reformasi Gereja. Tokoh yang cukup berpengaruh salah satunya yaitu John Calvin dari Perancis. Namun sayang sekali tidak semua orang memahami dan mengetahui mengenai sejarah reformasi Gereja. Oleh sebab itu diperlukan pengenalan sejak dini, terutama untuk anak usia 6-8 tahun. Dalam perancangan ini, Buku tersebut berbentuk buku cerita ilustrasi yang nantinya akan disajikan kepada anak Sekolah Minggu usia 6-8 tahun di GKKA-I Banjarbaru yang dimana gereja tersebut memliki latar belakang gereja reformed yang sesuai dengan tokoh dalam cerita tersebut. Buku dengan ukuran $21 \mathrm{~cm} \times 14,85 \mathrm{~cm}$ tersebut, memiliki gaya ilustrasi flat design dengan outline. Dengan jumlah halaman sebanyak 24 halaman, dijilid soft cover, serta dimuat dalam bentuk fisik (cetak). Kesimpulan dari perancangan ini yaitu menyajikan sebuah cerita ilustrasi bergambar kepada anak Sekolah Minggu usia 6-8 tahun di GKKA-I Banjarbaru, yang mengakat kisah sejarah reformasi Gereja sebagai bentuik pengenalan untuk umat Kristen sejak usisa dini melaui media buku cerita ilustrasi, poster, $P R$ package, Instagram feeds, stiker, tumbler, photocard, totebag, dan kaos dengan identitas perancangan.
\end{abstract}

Kata kunci: Buku Cerita Ilustrasi, Sejarah Reformasi Gereja, John Calvin

Citation Format: Purwanto, A.C., dan Nugroho, D.P. (2021). Perancangan Buku Ilustrasi Sejarah Reformasi Gereja, Adaptasi Karya Djoko Sulistyo Untuk Anak Usia 6-8 Tahun Di Sekolah Minggu GKKA-I Banjarbaru, Kalimantan Selatan. Prosiding Seminar Nasional Abdimas Ma Chung (SENAM), 2020, 50-68. 


\section{PENDAHULUAN}

Pengenalan pengetahuan akan sejarah merupakan salah satu cara untuk memahami asal mula suatu kebudayaan maupun peradaban yang menjadi sebuah refleksi dari kejadian yang ada dimasa lampau agar dapat menjadi pedoman baik dimasa yang akan datang. Hal ini didukung oleh pernyataan Iskandar (1996: p.1040) yang menyatakan bahwa sejarah berasal dari bahasa Arab yang artinya pohon. Namun dalam arti Iskandar (1996: p.1040) menyatakan bahwa dalam bahasa sehari-hari biasanya disebut dengan tarikh. Dalam bahasa Indonesia, kata sejarah disebut sebagai tarikh berarti waktu. Adapun dalam bahasa Yunani sejarah digambarkan dengan kata historia dalam artian lainnya bermakna ilmu. Namun dalam bahasa Inggris sejarah disebut history, yakni masa lalu. Dalam bahasa Prancis historie, bahasa Italia yaitu storia, bahasa Jerman geschichte, berarti yang terjadi dan dalam bahasa Belanda dikenal sebagai gescheiedenis. Selain itu, Waluyo (2005: p.17) mengatakan bahwa dalam perjalannya, tidak semua sejarah berkembang dengan baik. Kejadian baik dan buruk seringkali bercampur aduk menjadi sebuah sudut pandang yang membuat setiap manusia berhati-hati dalam menciptakan maupun mengembangkan peradaban yang ada. Oleh sebab itu betapa pentingnya sejarah dalam kehidupan manusia.

Secara khusus pula sejarah dalam kehidupan berkeagamaan. Salah satunya agama Kristen. Menurut Susanto (2019: p.1) Dalam agama Kristen, salah satu sejarah yang sangat penting yaitu sejarah tentang Gereja. Namun tidak semua orang paham dan mengerti tentang manfaat dan fungsi dari pemahaman akan sejarah berdirinya sebuah Gereja. Dalam Agama Kristen sejarah juga sebuah hal yang sangant penting. Salah satu sejarah yang mernarik yaitu sejarah yang berkaitan dengan reformasi Gereja. Dalam pergerakan reformasi gereja terdapat tokoh-tokoh yang berperan didalamnya. Tokoh yang cukup berpengaruh salah satunya yaitu John Calvin dari Perancis. Pemikiran tokoh tersebut juga nantinya yang dipakai sebagai doktrin dalam gereja Reformed, Injili dan Calvinis diseluruh dunia. Namun sayang sekali tidak semua orang memahami dan mengetahui mengenai sejarah reformasi Gereja.

Oleh sebab itu diperlukan pengenalan sejak dini, terutama untuk anak usia 6-8 tahun. Dalam perancangan ini, Buku tersebut berbentuk buku cerita ilustrasi yang nantinya akan disajikan kepada anak Sekolah Minggu usia 6-8 tahun di GKKA-I Banjarbaru yang dimana gereja tersebut memliki latar belakang gereja reformed yang sesuai dengan tokoh dalam cerita tersebut. 


\section{METODE PELAKSANAAN}

Dalam melakukan perancangan buku ilustrasi tersebut diperlukan metode pelaksanaan atau metode perancangan dalam membantu kelengkapan data yang telah didapatkan. Metode perancangan yang dipakai adalah model perancangan menurut Sanyoto (2006: p.38) dengan hasil implementasi dari penulis :

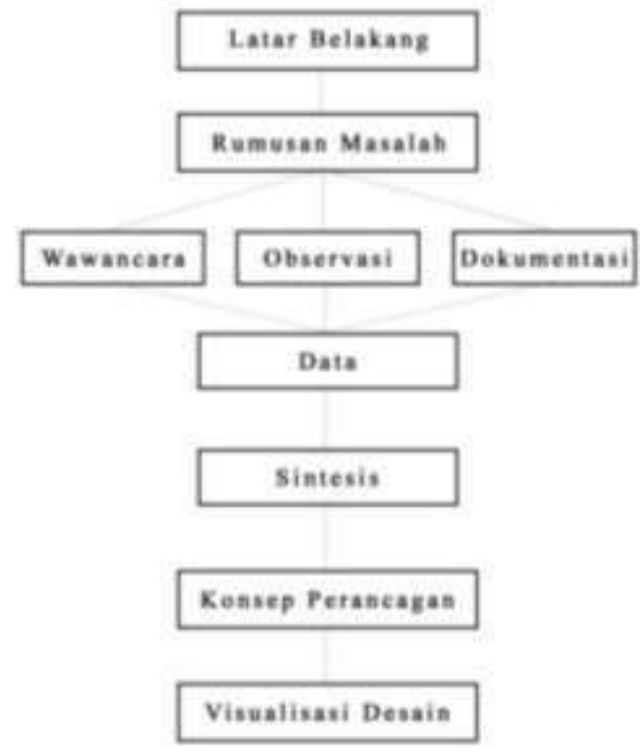

Gambar 1. Model Perancangan

(Sumber: Sanyoto, 2016)

Berdasarkan bagan tersebut, dimulai dari latar belakang masalah yang berisikan tentang penjelasan terkait dengan fenomena yang terjadi dilapangan dan kemudian dirumuskan dalam rumusan masalah dengan tujuan memecahkan serta mencari solusi dari permasalahan tersebut. Untuk tahapan selanjutnya adalah identifikasi data, dalam hal ini berkaitan dengan proses pengambilan data melalui wawaancara, observasi dan studi dokumentasi. Setelah data tersebut telah diperoleh, kemudian di kelola menjadi sebuah sintesis. Sintesis tersebut dipakai sebagai pedoman dalam konsep perancangan sehingga konsep yang diingkan dapat menjawab kebutuhan lapangan. Kemudian divisualisasikan menjadi sebuah produk yang berupa buku ilustrasi.

\section{HASIL DAN PEMBAHASAN}

\section{Konsep Pesan yang Ingin Disampaikan}

Bentuk ilustrasi pada buku tersebut diciptakan sebagai media utama dalam membantu anak usia 6-8 tahun di GKKA-I Banjarbaru memahami dan mengenal sejarah Reformasi Gereja yang dilakukan oleh John Calvin. Melaui hal tersebut maka buku ini 
memiliki nilai tambah dimana jarang sekali buku ilustrasi bergambar yang memiliki latar belakang cerita berupa sejarah Gereja, terutama Reformasi Gereja oleh John Calvin. Selain itu nilai tambah yang dapat ditemukan yaitu pengenalan budaya Perancis kepada anakanak usia 6-8 Tahun tersebut. dengan adanya penjabaran tersebut, perancang berharap agar buku tersebut kedepanya dapat membantu anak-anak dalam mengetahui sejarah latar belakang Gereja nya berdiri dan mengajarkan nilai-nilai agar selalu berpegang kepada kebenaran serta memperjuangkan kebenaran tersebut demi kemuliaan Nama Tuhan.

\section{Menentukan Alur Materi}

Sejarah Reformasi Gereja yang dituliskan dan diilustrasikan dalam buku tersebut dimulai dengan menekankan timeline kisah hidup John Calvin dari kelahiranya hingga wafatnya tokoh tersebut. ia mencari pengetahuan serta pengenalan akan Tuhan dan tidak menyimpan untuk dirinya sendiri namun berani melakukan pembaharuan yang didasarkan pada kebenaran Alkitab (Firman Tuhan).

Tabel 1. Narasi Sejarah Reformasi Gereja oleh John Calvin

\begin{tabular}{|c|c|}
\hline Bagian / Bab & Isi Narasi \\
\hline 1. Pembukaan & $\begin{array}{l}\text { Kisah ini dimulai dari kelahiran John Calvin atau dalam } \\
\text { bahasa Prancis disebut Jean Cauvin. Ia merupakan seorang } \\
\text { teolog Kristen Protestan yang dikenal karena } \\
\text { keterlibatannya dalam hal reformasi gereja. Ia disebut juga } \\
\text { sebagai reformator gereja yang berasal dari Prancis. Ia lahir } \\
\text { dari pasangan Gerard Calvin dan Jane Lefranc. John Calvin } \\
\text { merupakan anak pertama dari } 4 \text { bersaudara. Sehari-hari } \\
\text { Ayah John Calvin bekerja sebagai notaris Katedral dan } \\
\text { registrasi untuk pengadilan gerejawi. Kemudian, Ibunya } \\
\text { merupakan seorang pemilik penginapan dari Cambrai. } \\
\text { Semenjak Calvin berumur } 3 \text { tahun, ia ditinggal pergi oleh } \\
\text { ibunya karena ibunya meninggal dunia. }\end{array}$ \\
\hline $\begin{array}{l}\text { 2. Kedekatan John } \\
\text { Calvin dengan } \\
\text { Keluarga Hangst- } \\
\text { Genlis }\end{array}$ & $\begin{array}{l}\text { Semenjak kecil John Calvin dekat dengan keluarga } \\
\text { bangsawan terkenal di kota itu yaitu keluarga Hangst- } \\
\text { Genlis. Kedekatannya dengan keluarga tersebut } \\
\text { menimbulkan dampak yang sangat baik bagi Calvin. }\end{array}$ \\
\hline
\end{tabular}




\begin{tabular}{|c|c|}
\hline & $\begin{array}{l}\text { Karena pergaulannya tersebut ia memiliki sikap dan } \\
\text { gagasan serta pembawaan selayaknya bangsawan. }\end{array}$ \\
\hline $\begin{array}{l}\text { 3. Perjuangan } \\
\text { pengajuan Beasiswa } \\
\text { John Calvin yang } \\
\text { dilakukan oleh } \\
\text { ayahnya. }\end{array}$ & $\begin{array}{l}\text { Pada umur } 12 \text { tahun Calvin bakat dan kepandaian diatas } \\
\text { rata-rata anak pada seusianya dan ayah nya pun melihat } \\
\text { potensi pada diri Calvin. Ia berharap putranya tersebut } \\
\text { untuk menjadi seorang Pastor Gereja Katolik. Salah satu } \\
\text { usaha yang dilakukan oleh ayahnya yaitu itu } \\
\text { menyekolahkannya di College del la Marche, Paris. Di } \\
\text { sana ia belajar mengenai bahasa Latin dengan salah satu } \\
\text { guru yang terkenal pada saat itu yaitu Marthurin } \\
\text { Cordier. Kemudian John Calvin menyelesaikan } \\
\text { perkuliahannya di College de Montaigu dalam bidang } \\
\text { filsafat. Pada saat itu keluarga Calvin tidak begitu kaya. } \\
\text { Untungnya Ayah Calvin memiliki kedekatan dan dan } \\
\text { dukungan dari gereja. Dari situ, Calvin mendapatkan } \\
\text { beasiswa dari Gereja. Calvin sangat bertanggung jawab } \\
\text { dalam kegiatan belajar dan sekolahnya. }\end{array}$ \\
\hline $\begin{array}{l}\text { 4. Kematian Ayah John } \\
\text { Calvin }\end{array}$ & $\begin{array}{l}\text { Pada awalnya Ayah Calvin menginginkan Calvin menjadi } \\
\text { seorang Pastor. Akan tetapi ia berubah pikiran agar anaknya } \\
\text { belajar ilmu hukum. Sehingga di umurnya yang ke-14 } \\
\text { tahun Ia masuk ke Universitas Paris untuk belajar bidang } \\
\text { humaniora dan hukum. Ia berangkat bersama tiga pemuda } \\
\text { dari keluarga Hangst. Pada tahun } 1532 \text { John Calvin } \\
\text { dijadikan sebagai doktor hukum di Orleans. Namun } \\
\text { Calvin tidak berubah, ia tetap memiliki kesukaan dibidang } \\
\text { teologi sembari ia menyelesaikan studinya. Suatu saat } \\
\text { Ayah Calvin menyuruhnya untuk kembali ke Noyon dan } \\
\text { didapatinya bahwa Ayahnya sakit keras. Tidak lama setelah } \\
\text { itu Ayahnya meninggal dunia dan hal tersebut membuat } \\
\text { Calvin merasa sangat sedih dan menjadi seorang anak yatim } \\
\text { piatu. }\end{array}$ \\
\hline
\end{tabular}




\begin{tabular}{|c|c|}
\hline $\begin{array}{l}\text { 5. Awal Pergerakan } \\
\text { Reformasi Gereja } \\
\text { oleh John Calvin }\end{array}$ & $\begin{array}{l}\text { Setelah kepergiaan ayah nya,Calvin menulis banyak buku } \\
\text { yang bersangkutan dengan Kitab Suci. Dari sana, } \\
\text { seringkali dipanggil untuk memberikan khotbah di gereja } \\
\text { dan Ia dikenal sebagai pengkhotbah yang hebat. Dengan } \\
\text { kemampuan berpikirnya yang ia membuat banyak orang } \\
\text { kagum terhadapnya. Pada saat itu perkembangan baru di } \\
\text { bidang agama terjadi besar-besaran di Perancis. Salah } \\
\text { satunya yaitu dengan adanya pembaharuan yang dilakukan } \\
\text { oleh Martin Luther di Jerman yang dampaknya terasa } \\
\text { begitu besar hingga ke Perancis. Banyak orang yang } \\
\text { kemudian menganut paham pembaharuan tersebut. Pada } \\
\text { saat itu John Calvin juga mulai melakukan pertobatan. } \\
\text { Namun ia masih menjadi anggota Gereja yang baik tetapi } \\
\text { dengan pelan melakukan pembaharuan meskipun tidak } \\
\text { berhasil. Selain itu Calvin melakukan pembaharuan dengan } \\
\text { menerbitkan bukunya yang sangat terkenal yaitu“Institutio" } \\
\text { atau lengkapnya disebut "Christianae Religionis Institutio" } \\
\text { yang berati buku pengajaran agama Kristen. }\end{array}$ \\
\hline $\begin{array}{l}\text { 6. Perjalanan Menuju } \\
\text { Jenewa. }\end{array}$ & $\begin{array}{l}\text { Pada saat itu Calvin menyampaikan tulisanya kepada Raja } \\
\text { Frans I dengan tujuan agar raja tidak terpengaruh akan } \\
\text { pemberitaan bohong tentang pergerakan pembaharuan } \\
\text { Gereja. Sehingga Calvin membuat masyarakat geram } \\
\text { terhadapnya.Akhirnya pergi dari perancis menuju ke Italia } \\
\text { Utara dan menginap di Istana permaisuri Reene de } \\
\text { France, di kota Ferrara. Tidak lama setelah itu John Calvin } \\
\text { mendengar bahwa Perancis melakukan pengampunan } \\
\text { kepada pihak pembaharuan gereja. Namun sebelum ia ke } \\
\text { Perancis ia sempat melewati kota Jenewa di Swiss. } \\
\text { Kemudian tahun } 1536 \text { ia akhirnya memutuskan menetap di } \\
\text { Jenewa, setelah bertemu dengan seorang reformator } \\
\text { terkenal di kota itu yaitu William Farel. Dia menawarkan } \\
\text { John Calvin untuk melayani Jemaat. Namun pada saat itu }\end{array}$ \\
\hline
\end{tabular}




\begin{tabular}{|c|c|}
\hline & $\begin{array}{l}\text { Calvin merasa bahwa tugasnya bukan untuk melayani } \\
\text { jemaat. Kemudian Farel pun mengatakan kepadanya bahwa } \\
\text { ia seorang pengecut. Katanya saat itu "Saudara Calvin, } \\
\text { ternyata saudara hanya mementingkan diri sendiri. Kalau } \\
\text { demikian saya atas nama Allah yang maha kuasa } \\
\text { menyatakan bahwa apabila saudara menolak permintaan } \\
\text { ini, maka Allah akan mengutuk saudara, sebab saudara } \\
\text { hanya mencari kepentingan diri sendiri dan mengabaikan } \\
\text { kemuliaan Kristus". Dari sana Ia berpikir lalu Ia } \\
\text { memutuskan akhirnya untuk berjanji kepada } \\
\text { William bahwa ia akan bekerja bahu-membahu untuk } \\
\text { pekerjaan Tuhan di kota Jenewa. }\end{array}$ \\
\hline 7. Konflik di Jenewa. & $\begin{array}{l}\text { Ketika John Calvin dilantik sebagai Pendeta di Gereja } \\
\text { Jenewa. Ia mela- kukan banyak perubahan, salah satunya } \\
\text { yaitu tentang Perjamuan Kudus. Dimana Perjamuan } \\
\text { Kudus hanya bisa diikuti Jemaat dengan hati yang suci } \\
\text { dan penuh kerendahan hati. Oleh sebab itu orang- orang } \\
\text { yang masih cemar hatinya dan menjadi sandungan bagi } \\
\text { orang lain diharapkan untuk tidak mengikuti perjamuan } \\
\text { tersebut. Banyak orang yang tidak senang dengan } \\
\text { peraturan tersebut termasuk wali- kota yang baru } \\
\text { terpilih. Sehingga pejabat setempat memutuskan untuk } \\
\text { mengusir mereka berdua dari kota tersebut. Dengan } \\
\text { keadaan seperti itu, semangat pelayanan mereka tidak } \\
\text { lesu. Namun semakin berkobar-kobar. }\end{array}$ \\
\hline $\begin{array}{l}\text { 8. Pernikahan dengan } \\
\text { Idette de Bure. }\end{array}$ & $\begin{array}{l}\text { Pada tahun } 1538 \text { di bulan september, Calvin kembali ke } \\
\text { kota Strasbourg kota tersebut telah mengalami Reformasi } \\
\text { Gereja sebelumnya sejak tahun 1524) dan melayani jemaat } \\
\text { pelarian yang berjumlah kira-kira } 500 \text { orang. Pada suatu } \\
\text { hari ia berniat untuk menikah dalam menunjukan respon } \\
\text { positifnya terhadap pernikahan daripada kehidupan selibat. } \\
\text { Kemudian pada tahun } 1539 \text { ia menikah dengan Idette de }\end{array}$ \\
\hline
\end{tabular}




\begin{tabular}{|c|c|}
\hline & $\begin{array}{l}\text { Bure. Seorang Janda yang dulunya anggota Anabaptis di } \\
\text { Strasbourg, Perancis. Idette Memiliki seorang anak laki-laki } \\
\text { dan perempuan dari almarhum suaminya. Namun hanya } \\
\text { anak perempuannya yang pindah bersamanya ke Jenewa. } \\
\text { Dalam pernikahanya, Calvin dan Idette dikaruniai seorang } \\
\text { anak laki-laki. Namun tidak lama setelah itu anak laki-laki } \\
\text { tersebut meninggal dunia. Pada tahun } 1549 \text {, ia kehilangan } \\
\text { istrinya. Namun itu tidak menghalangi semangat nya dalam } \\
\text { melayani di Gereja. }\end{array}$ \\
\hline $\begin{array}{l}\text { 9. Perlawanan John } \\
\text { Calvin terhadap } \\
\text { Ajaran Sesat I : } \\
\text { Michael Servetus. }\end{array}$ & $\begin{array}{l}\text { Pada bulan September } 1541 \text { bertolak ke Jenewa atas } \\
\text { permintaan dewan kota yang baru yang mendukung Calvin } \\
\text { atas gerakan pembaharuan Gereja yang dilakukannya. } \\
\text { Ketika ia sampai disana, ia membuat tatanan-tatanan baru } \\
\text { untuk rancangan tata gereja. Dirasa cukup berat bagi } \\
\text { banyak orang dan mereka mulai menentang peraturannya. } \\
\text { Bahkan pada tahun } 1553 \text { partai oposisi berhasil menang } \\
\text { dalam pemilihan dewan kota dan kedudukan Calvin yang } \\
\text { sebelumnya di dukung oleh partai yang berkuasa pada } \\
\text { zaman itu menjadi terguncang. Namun Calvin tidak pantang } \\
\text { menyerah karena baginya Kristus harus ditinggikan, Pada } \\
\text { saat itu tokoh yang paling keras menentang Calvin yaitu } \\
\text { Michael Servetus. Tokoh tersebut menolak ajaran Kristen } \\
\text { tentang Trinitas, serta menolak Ketuhanan Yesus. Selain itu } \\
\text { Servet juga menolak adanya dosa warisan serta menolak } \\
\text { baptisan anak-anak. Oleh sebab itu Calvin menganggap } \\
\text { bahwa hal ini sudah menyimpang. Pada saat itu pihak } \\
\text { Katolik Roma juga sangat marah terhadap ajaran Servet } \\
\text { tersebut. Hingga akhirnya Gereja bertindak sangat tegas } \\
\text { yaitu itu dengan cara Servet diadili secara keras dan } \\
\text { ditangkap.Ia dianggap memutarbalikkan ajaran } \\
\text { Alkitab. Akhirnya melalui berbagai pertimbangan, Ia } \\
\text { menerima hukuman yang sangat berat. }\end{array}$ \\
\hline
\end{tabular}




\begin{tabular}{|c|c|}
\hline $\begin{array}{l}\text { 10. Perlawanan John } \\
\text { Calvin terhadap } \\
\text { Ajaran Sesat II : } \\
\text { Bolsec. }\end{array}$ & $\begin{array}{l}\text { Selain itu Calvin juga mendapat pertentangan mengenai } \\
\text { ajarannya yang berupa predestinasi. Orang yang } \\
\text { menentangnya yaitu seorang bekas Pastor Katolik bernama } \\
\text { Bolsec. Predestinasi adalah penentuan Allah tentang siapa } \\
\text { yang akan menerima keselamatan atau sebaiknya menolak } \\
\text { keselamatan itu sebelum orang itu lahir. Menurut Bolsec } \\
\text { ajaran Calvin tentang predestinasi itu bertentangan dengan } \\
\text { ajaran Alkitab. Oleh sebab itu dari sana Bolsec juga mulai } \\
\text { melemparkan tuduhan-tuduhan yang tidak baik kepada } \\
\text { Calvin didasari atas ketidaksenangannya kepada pribadi } \\
\text { Calvin. Apa yang dilakukan Bolsec mendapat reaksi keras } \\
\text { dari gereja-gereja di Jenewa serta orang-orang yang } \\
\text { membela Calvin. Kemudian gereja-gereja tidak } \\
\text { menghendaki kehadiran Bolsec lagi sehingga ia dituntut } \\
\text { hukuman berat. Namun setelah pengadilan yang panjang } \\
\text { diputuskan agar Bolsec diusir dari Jenewa. }\end{array}$ \\
\hline $\begin{array}{l}\text { 11. Calvin di Akhir } \\
\text { Masa Hidupnya. }\end{array}$ & $\begin{array}{l}\text { Di dalam kehidupan, ini Calvin pun mengalami persoalan } \\
\text { terutama dengan kesehatannya. Hal itu dibuktikan ketika } \\
\text { ia melakukan pemberitaan firman Tuhan pada tanggal } 2 \\
\text { Februari 1564, hampir saja ia tidak dapat selesaikankan. } \\
\text { Akibat nafasnya sesak dan sulit berbicara. Dalam } \\
\text { keadaannya yang terakhir Ia menggunakan tandu untuk } \\
\text { mengadakan Perpisahan dengan dewan kota. Di akhir masa } \\
\text { hidupnya tersebut ia meminta maaf kepada warga-warga } \\
\text { gereja dan juga dengan jujur minta maaf kepada pemerintah } \\
\text { serta kawan-kawannya atas tindakannya yang keras selama } \\
\text { ini. Pada hari Sabtu } 27 \text { Mei } 1564 \text { pelayan firman Tuhan itu } \\
\text { meninggal dunia. Seluruh kota Jenewa berduka dan banyak } \\
\text { orang dari kalangan tinggi maupun kalangan rendah } \\
\text { kehilangan tokoh tersebut. }\end{array}$ \\
\hline
\end{tabular}




\section{Penentuan Judul dan Karakter}

Dalam perancangan ini, judul buku yang akan diterapkan yaitu "Sejarah Reformasi Gereja : John Calvin Tokoh Reformator dari Perancis”. Pemilihan judul buku tersebut didasarkan oleh cakupan yang tertera di judul merangakap seluruh isi cerita. Untuk alternative lainnya, perancang memilih judul buku berupa "Pahlawan Reformasi Gereja : John Calvin dari Perancis". Karakter utama dari buku tersebut adalah John Calvin. Sehingga segala fokus cerita diarahkan agar tokoh tersebut dapat diteladani oleh anak-anak yang menjadi sasaran terutama anak-anak usia 8-6 tahun di GKKA-I Banjarbaru.

\section{Pemilihan Warna}

Warna yang digunakan oleh perancang dalam menciptakan karya ini yaitu warnawarna natural yang memberikan kesan kehangatan dan terisnpirasi dari warna-warni pastel dan cerah. Sehingga dapat menimbulkan kesan yang menyenangkan serta cerah dan dihartapkan agar dapat disukai oleh pembaca pada perancangan karya ini.

\section{Pemilihan Tipografi}

Dalam perancangan buku ilustrasi tersebut, perancang memilih menggunakan jenis tipografi serif yaitu dengan font Arial sebagai header font (untuk judul) dengan ukuran 1824 pt. Kemudian untuk footer font atau font isian konten, perancang menggunakan font Myriad Pro, dengan jenis tipografi serif dengan ukuran 14 - 20 pt.. Kedua font tersebut dipakai oleh perancang karena bentuknya yang minimalist dan menyenankan bila digunakan untuk menceritakan sebuah cerita sejarah kepada anak-anak.

\section{Layout}

Penataan layout yang dilakukan oleh perancang yaitu bersfiat full left and right image tanpa ruang kosong untuk peletakan narasi, lalu sebelah kanan gambar serta sebelah kiri tulisan dengan beberapa ilustrasi sebagai dekor, dan 75\% halaman berisi gambar serta sisanya diberi space untuk meletakan narasi dari cerita tersebut.

\section{Penampilan Buku}

Dalam perancangan tugas akhir perancang, media utama yang menjadi topic bahasan "Perancangan Buku Ilustrasi Sejarah Reformasi Gereja Untuk Anak Usia 6-8 Tahun Di Sekolah Minggu GKKA-I Banjarbaru, Kalimantan Selatan” adalah buku ilustrasi bergambar.dengan ukuran panjang $21 \mathrm{~cm}$ dan lebar 14,85 cm (ukuran kertas A4) full color. Dengan jumlah halaman 22 ilustrasi bergambar dengan tambahan satu lembar permainan, 
serta tambahan lain berupa lembar penerbit, lembar judul, dan 2 halaman penuh untuk quotes dari tokoh John Calvin. Dari hal-hal tersebut maka berikut merupakan hasil perancangan tersebut.

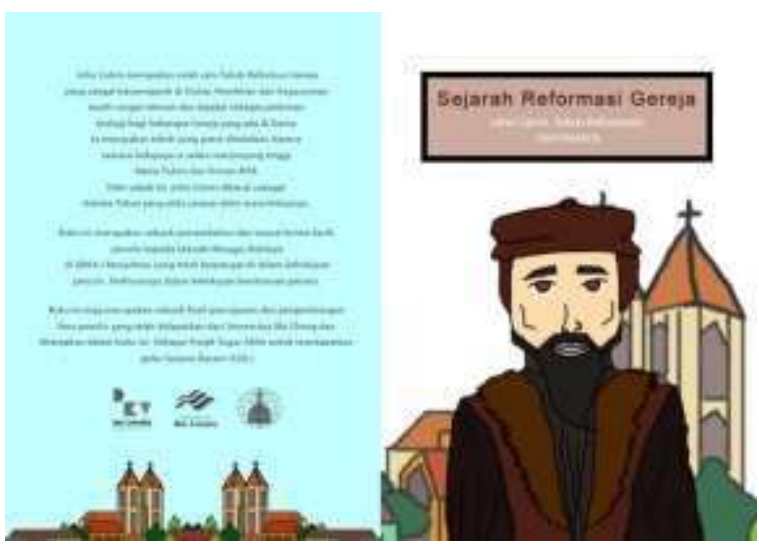

Gambar 1. Cover Buku

(Sumber: Dokumentasi Pribadi)

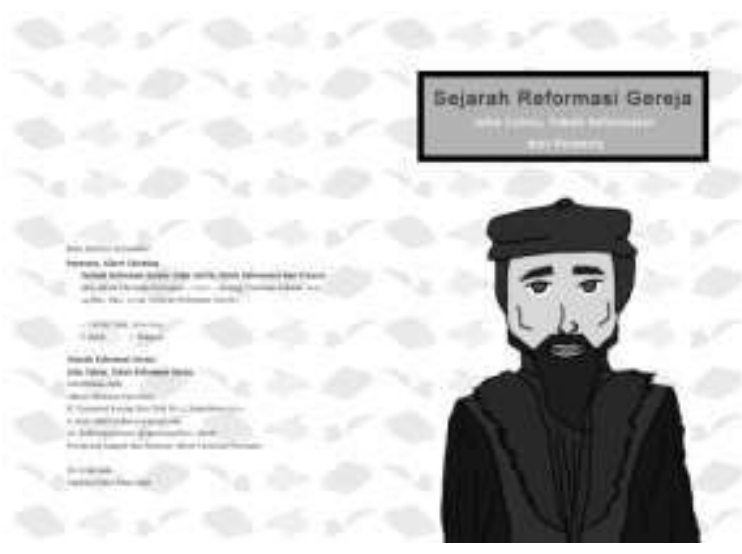

Gambar 2. Lembar Penerbit dan Judul Buku

(Sumber: Dokumentasi Pribadi)

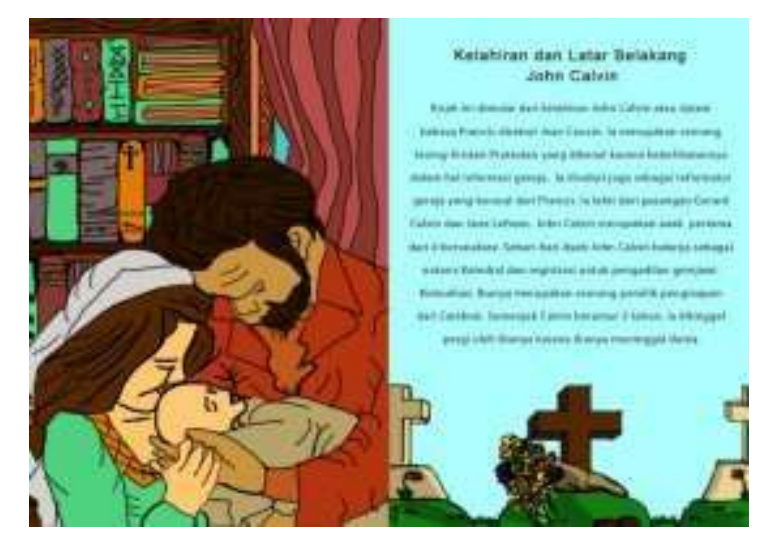

Gambar 3. Halaman 1 dan 2 Buku

(Sumber: Dokumentasi Pribadi) 


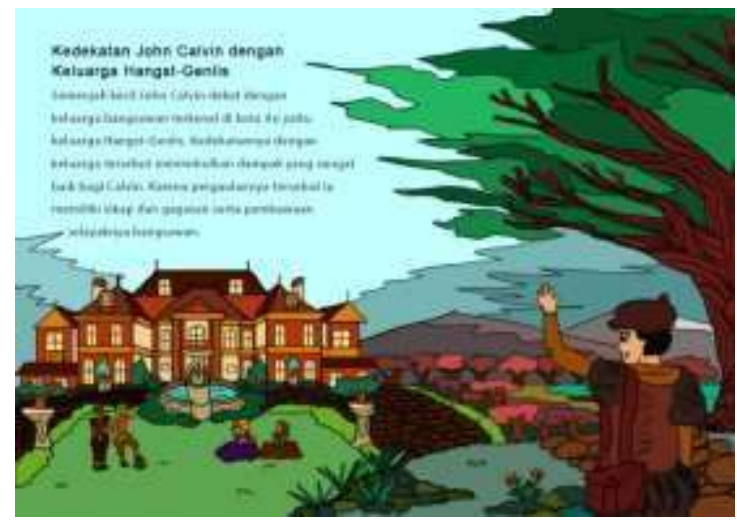

Gambar 4. Halaman 3 dan 4 Buku

(Sumber: Dokumentasi Pribadi)

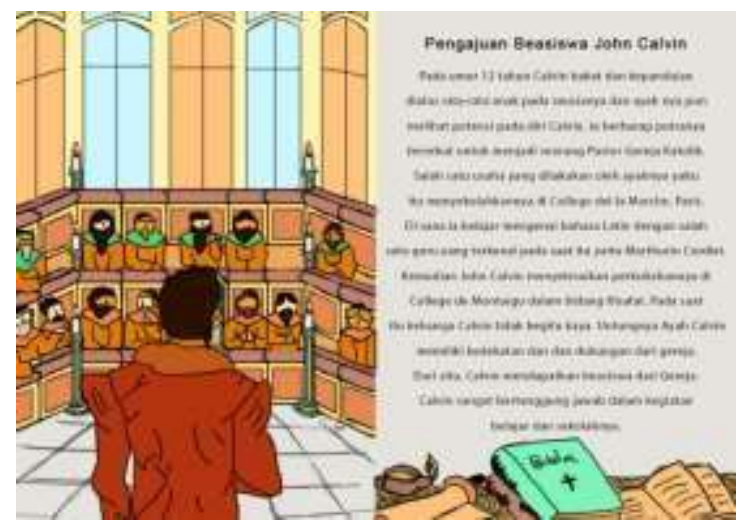

Gambar 5. Halaman 5 dan 6 Buku

(Sumber: Dokumentasi Pribadi)

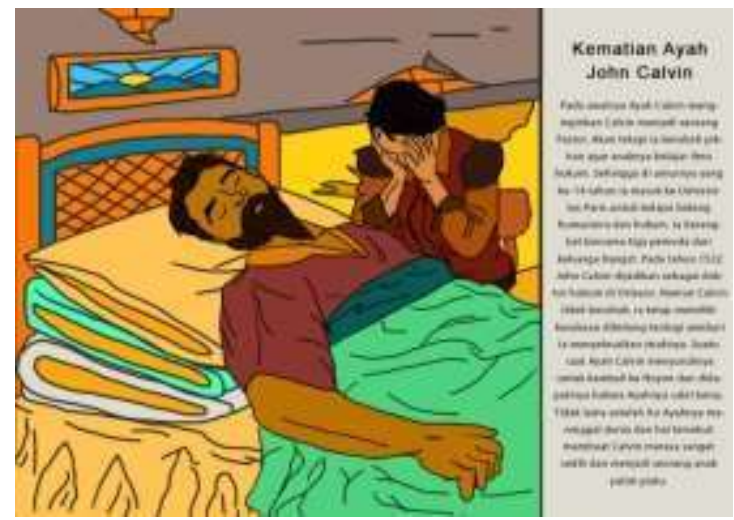

Gambar 6. Halaman 7 dan 8 Buku

(Sumber: Dokumentasi Pribadi) 


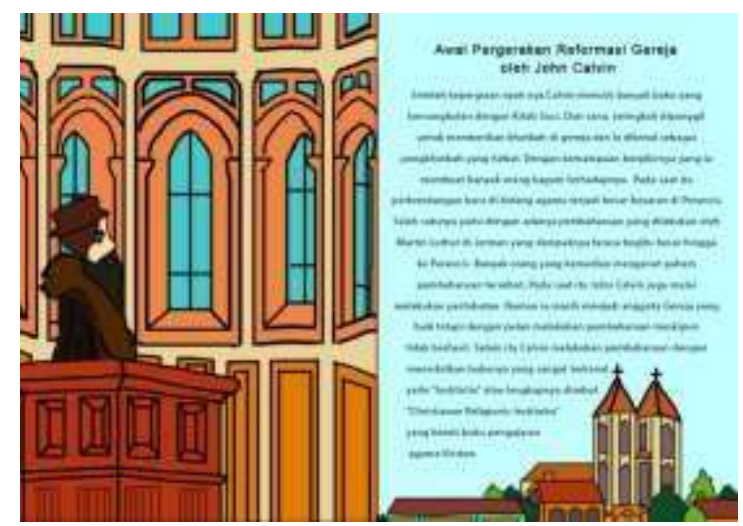

Gambar 7. Halaman 9 dan 10 Buku

(Sumber: Dokumentasi Pribadi)

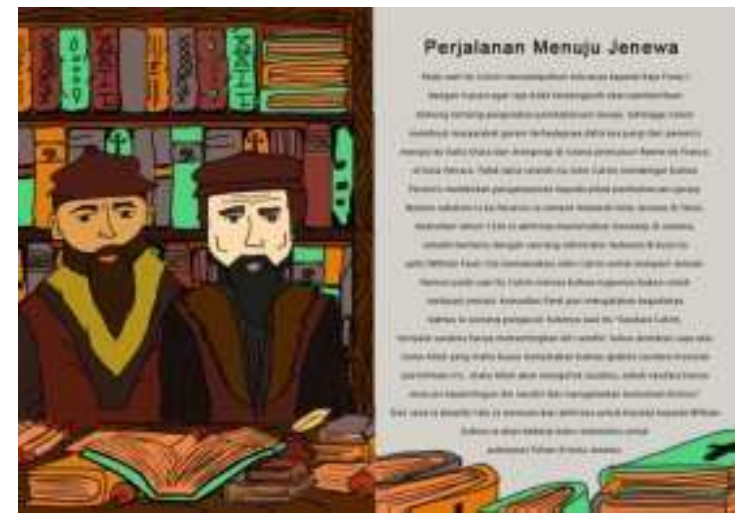

Gambar 8. Halaman 11 dan 12 Buku

(Sumber: Dokumentasi Pribadi)

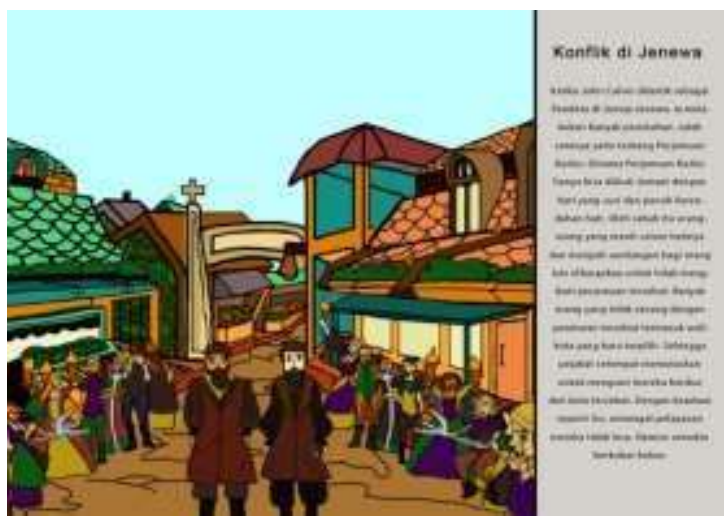

Gambar 9. Halaman 13 dan 14 Buku

(Sumber: Dokumentasi Pribadi) 


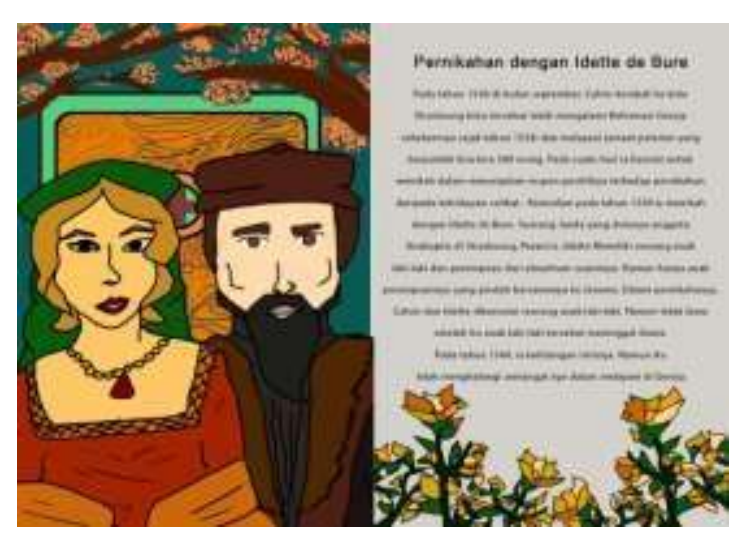

Gambar 10. Halaman 15 dan 16 Buku

(Sumber: Dokumentasi Pribadi)

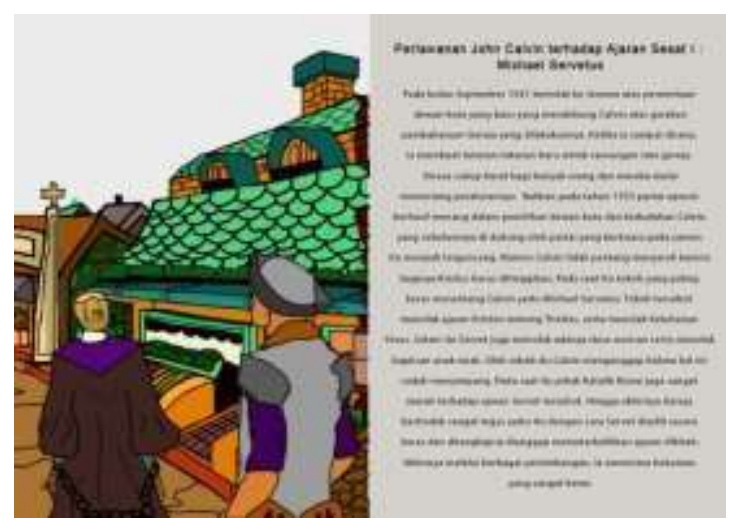

Gambar 11. Halaman 17 dan 18 Buku (Sumber: Dokumentasi Pribadi)

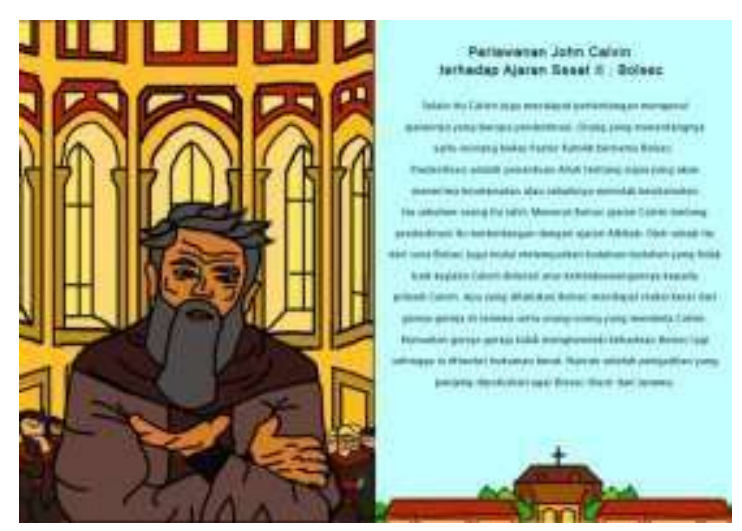

Gambar 12. Halaman 19 dan 20 Buku (Sumber: Dokumentasi Pribadi) 

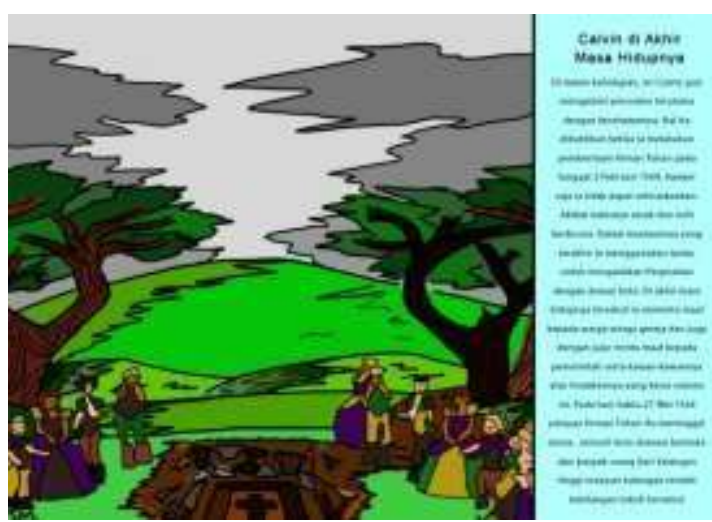

Gambar 13. Halaman 21 dan 22 Buku

(Sumber: Dokumentasi Pribadi)

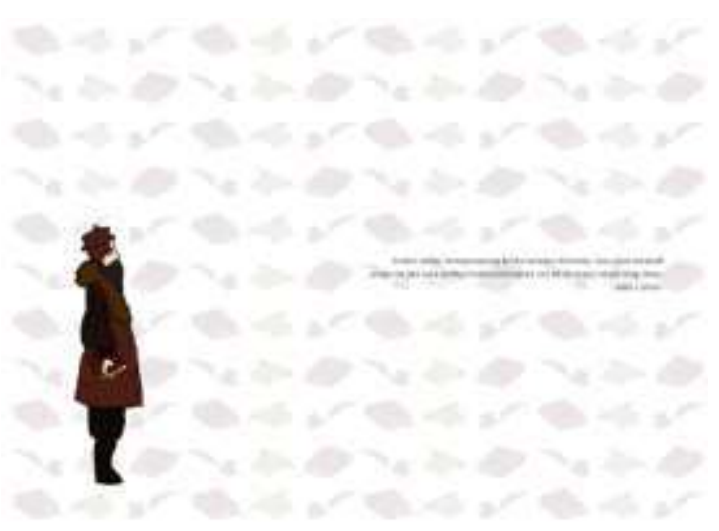

Gambar 14. Penutup dan Kata Bijak

(Sumber: Dokumentasi Pribadi)

\section{Media Pendukung}

Agar buku ilustrasi tersebut dapat dikenal dengan baik oleh banyak orang dan juga dapat memudahkan pembaca dalam menegenal buku tersebut, maka diperlukan sebuah media lain guna mendukung media utama dalam perancangan buku ilustrasi tersebut. berdasarkan apa yang telah disebutkan oleh perancang dalam bab 3, maka berikut merupakan hasil serta pemaparannya. Media pendukung tersebut berupa poster, $P R$ package, Instagram feeds, stiker, tumbler, photocard, totebag, dan kaos dengan identitas perancangan. 


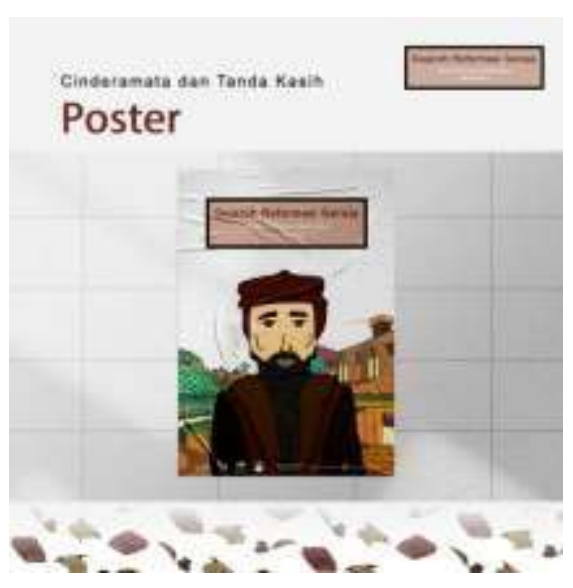

Gambar 15. Poster

(Sumber: Dokumentasi Pribadi)

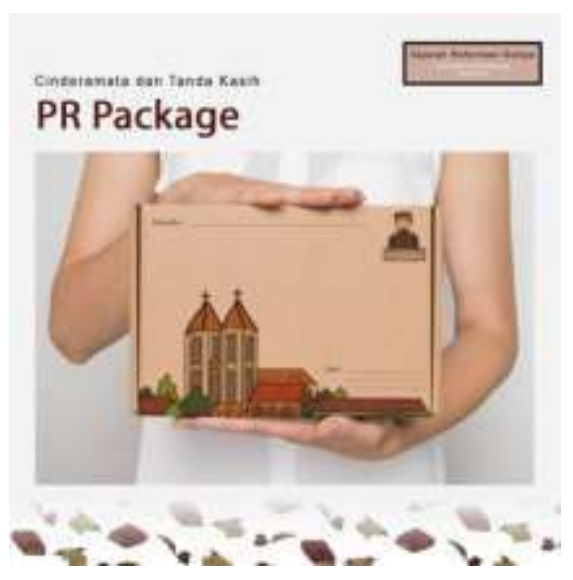

Gambar 16. PR Package

(Sumber: Dokumentasi Pribadi)

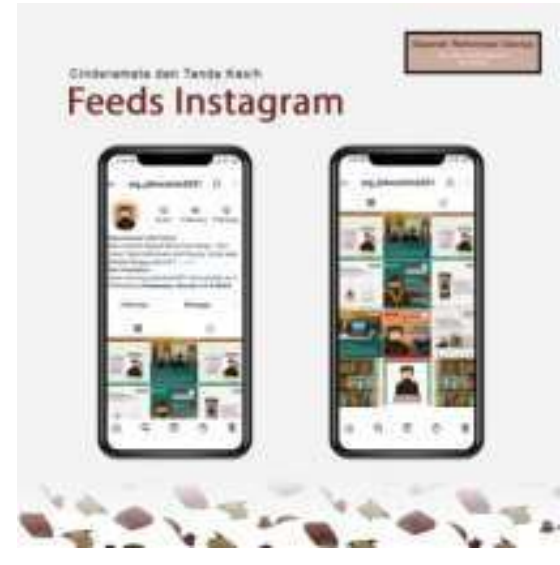

Gambar 17. Instagram Feeds

(Sumber: Dokumentasi Pribadi) 


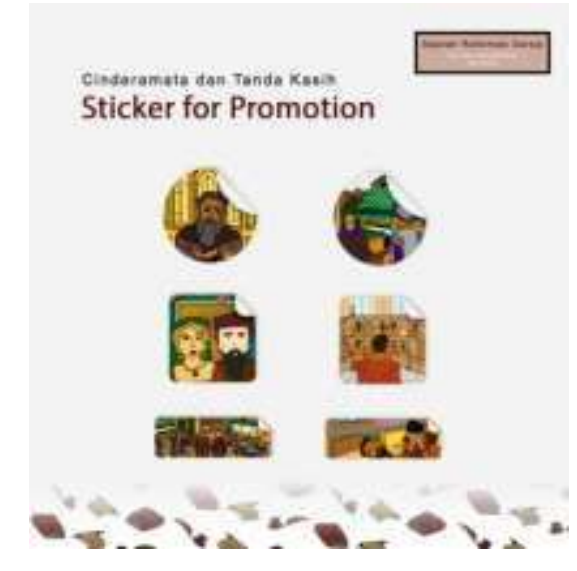

Gambar 18. Stiker

(Sumber: Dokumentasi Pribadi)

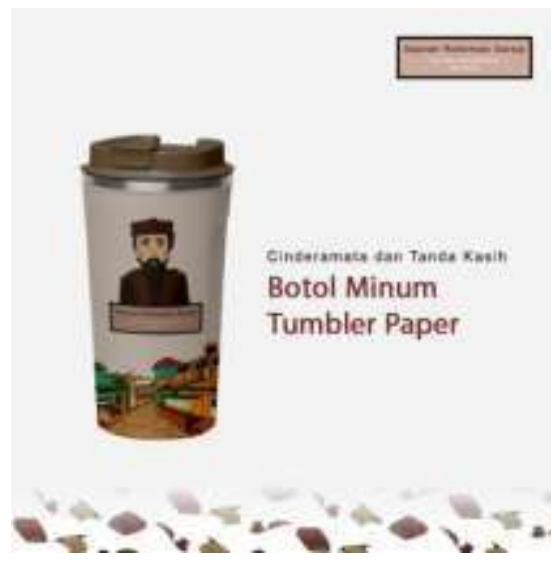

Gambar 19. Tumbler

(Sumber: Dokumentasi Pribadi)

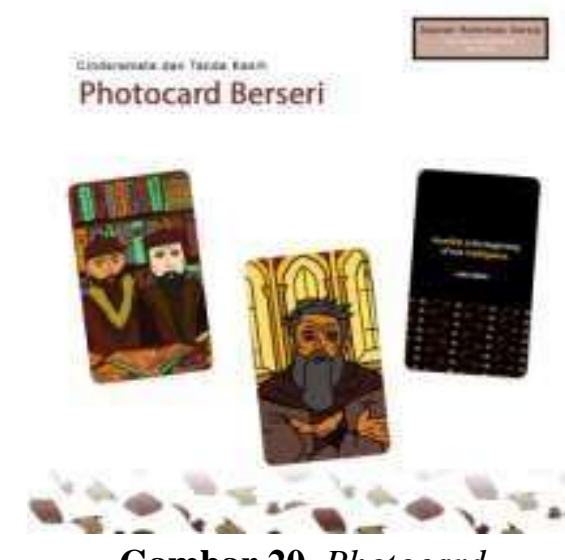

Gambar 20. Photocard

(Sumber: Dokumentasi Pribadi) 


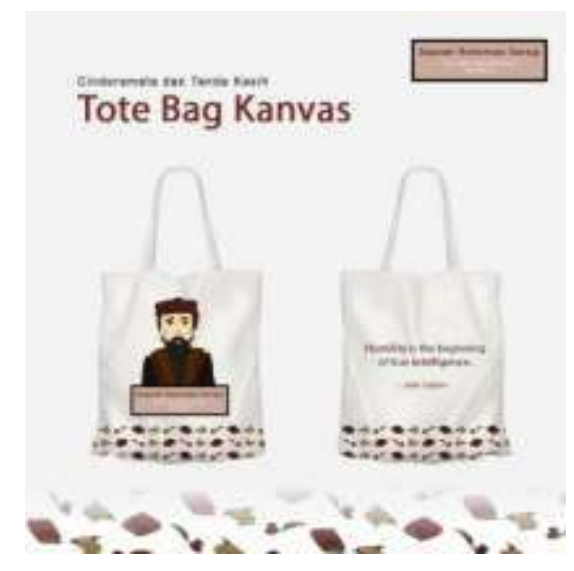

Gambar 21. Tote Bag

(Sumber: Dokumentasi Pribadi)

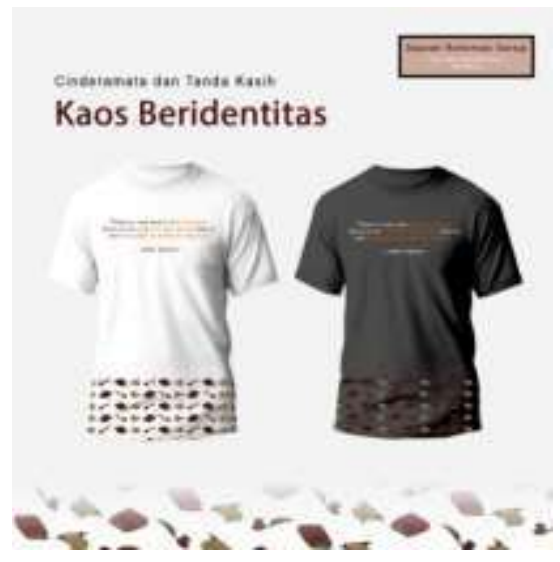

Gambar 22. Kaos Beridentitas

(Sumber: Dokumentasi Pribadi)

\section{KESIMPULAN}

Kesimpulan dari perancangan telah sesuai dengan kaidah serta teori yang diimplemetasikan dalam bentuk sebuah cerita ilustrasi bergambar kepada anak Sekolah Minggu usia 6-8 tahun di GKKA-I Banjarbaru, yang mengakat kisah sejarah reformasi Gereja sebagai bentuk pengenalan untuk umat Kristen sejak usisa dini melaui media buku cerita ilustrasi, poster, PR package, Instagram feeds, stiker, tumbler, photocard, totebag, dan kaos dengan identitas perancangan. Meskipun tidak terdapat evaluasi dari pembaca yang dimuat dalam makalah tugas akhir ini sehingga tidak diketahui secara pasti respon dari pembaca. Namun jika mengikuti alur dan tahapan yang ada maka muncul keyakinan, bahwa seharunya buku tersebut telah seusai dengan saran yang ada. 


\section{UCAPAN TERIMA KASIH}

Ucapan terima kasih ditujukan kepada semua pihak yang terlibat dalam perancangan buku ilustrasi tersedbut, dari awal pengerjaan hingga akhirnya. Terlebih lagi kepada para dosen pembimbing Bapak Aditya Nirwana, S.Sn., M.Sn., Bapak Didit Prasetyo Nugroho, S.Sn., M.Sn., dan Bapak Bintang Pramudya Putra Prasetya, S.Sn., M.Ds., Bapak Jonathan Budiman, S.T. selaku kepala Sekolah Minggu Haleluya di GKKAI Banjarbaru, para narasumber, keluarga serta teman-teman.

\section{DAFTAR PUSTAKA}

Iskandar, Tengku. 1996. Kamus Dewan Edisi Kedua. Kuala Lumpur. Dewan Bahasa dan Pustaka.

Sanyoto, Sadjiman Ebdi. 2006. Metode Perancangan komunikasi Visual Periklanan. Penerbit Dimensi Press, Yogyakarta.

Susanto, H. 2019. Teologi Ditinjau dari Perspektif Sejarah Gereja, Yogyakarta. Sekolah Tinggi Teologi Injili Indonesia, diakses pada tanggal 5 Mei 2021, $<$ https://osf.io/fxysc/download>

Waluyo, L. 2005. Evolusi Organik. Penerbit UMM Press, Malang.

(C) 2021 by authors. Content on this article is licensed under a Creative Commons Attribution 4.0 International license. (http://creativecommons.org/licenses/by/4.0/). 